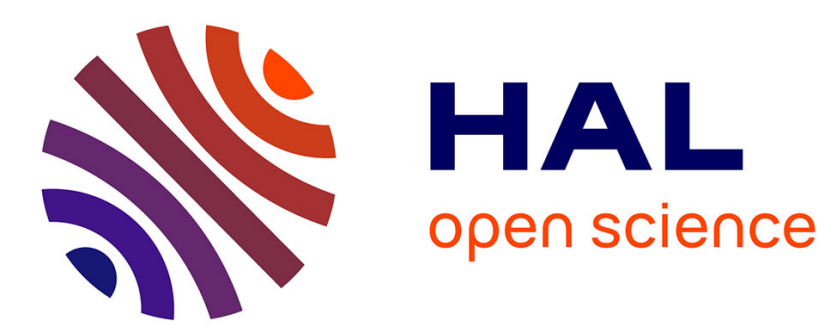

\title{
An atmospheric pressure plasma source driven by a train of monopolar high voltage pulses superimposed to a dc voltage \\ O.S. Stoican
}

\section{- To cite this version:}

O.S. Stoican. An atmospheric pressure plasma source driven by a train of monopolar high voltage pulses superimposed to a dc voltage. European Physical Journal: Applied Physics, 2011, 55 (3), 10.1051/epjap/2011100184 . hal-00724136

\section{HAL Id: hal-00724136 \\ https://hal.science/hal-00724136}

Submitted on 18 Aug 2012

HAL is a multi-disciplinary open access archive for the deposit and dissemination of scientific research documents, whether they are published or not. The documents may come from teaching and research institutions in France or abroad, or from public or private research centers.
L'archive ouverte pluridisciplinaire HAL, est destinée au dépôt et à la diffusion de documents scientifiques de niveau recherche, publiés ou non, émanant des établissements d'enseignement et de recherche français ou étrangers, des laboratoires publics ou privés. 


\title{
An atmospheric pressure plasma source driven by a train of monopolar high voltage pulses superimposed to a dc voltage.
}

\author{
A plasma source driven by a train of hv pulses combined with a dc voltage \\ O. S. Stoican ${ }^{a}$
}

National Institute for Laser, Plasma and Radiation Physics (INFLPR), 409 Atomistilor St. PO Box MG36, 077125, Magurele, Romania

Received: date / Revised version: date

\begin{abstract}
An atmospheric pressure plasma source supplied by an electrical circuit consisting of two voltages sources in parallel connection, is reported. One of them is a low power self oscillating flyback converter which produces negative voltage pulses with an amplitude of several kilovolts. The high voltage pulses are necessary to ignite an electrical discharge between the electrodes at atmospheric pressure. An additional dc source delivering several hundred of volts at a few hundred of milliamps is used to sustain the electrical discharge. The circuit configuration allows the control of the discharge current over a wide range, in a simple manner. By using argon as a working gas, a stable plasma plume up to $8 \mathrm{~mm}$ long can be obtained either in a transferred or non-transferred arc mode.
\end{abstract}

\section{Introduction}

Due to a large diversity of possible applications [1-5], development of the devices aimed to generate atmospheric pressure plasmas has attracted a significant research effort in recent years. In order to ignite an electrical discharge at atmospheric pressure and maintain the plasma in a regime appropriate to a specific application, various electrical supply schemes, including superposition of

\footnotetext{
a e-mail: stoican@infim.ro
}

a time-varying periodic voltage to a dc voltage, have been described in previous research [6-10]. For the atmospheric pressure plasma source presented in this paper, the high voltages pulses produced by a self oscillating flyback converter $(\mathrm{FBC})$ are superimposed to a relatively low dc voltage. A FBC is very simple and has a good efficiency because it can be connected to the load without a ballast resistor. This approach was inspired by the electric supply circuit of the high intensity discharge arc lamps [11-14]. 
These devices require a high voltage pulse to initiate an arc discharge between the electrodes. Once the arc discharge has been ignited, another electrical circuit supplies the proper voltage and current for the discharge to run.

\section{Plasma source description}

The schematic drawing of the plasma source is shown in

Figure 1. The cathode consists of a copper wire with a diameter $d=1.75 \mathrm{~mm}$. The cathode is centred in a nozzle shaped cavity made in a solid cylindrical block of aluminium. The extreme diameters of the cavity cross sections are $D_{\min }=9 \mathrm{~mm}$ and $D_{\max }=30 \mathrm{~mm}$ respectively, while the total length is $43 \mathrm{~mm}$. The length $L_{0}$ of the cathode existing inside the small-diameter cavity can be adjusted to a range of 5-15 $\mathrm{mm}$. An insulator disk closes the larger diameter end of the cavity enabling mechanical support and electrical isolation of the cathode. The working gas is introduced through an inlet positioned near the cavity end and perpendicular to its axis. Such geometry allows the vortex-stabilisation of the arc. The aluminium cylinder is connected to the ground and plays the role of the anode. Natural convection of the ambient air ensures anode cooling. The smaller diameter end of the cavity is covered by a thin insulator disk having a central output hole of $3 \mathrm{~mm}$ in diameter. Both insulators disks are made of Teflon. The output hole limits the cross section of the working gas stream and shapes the plasma jet.

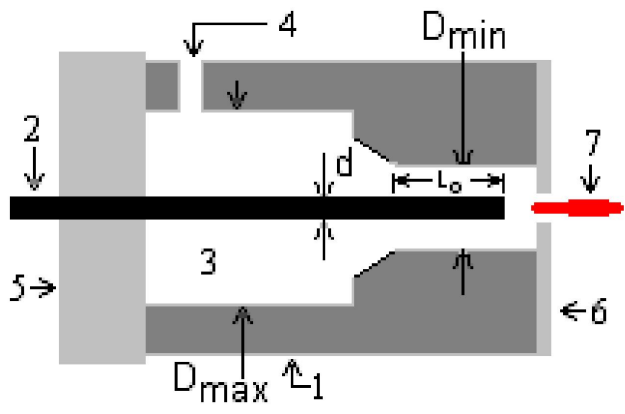

Fig. 1. Schematic drawing of the plasma source. 1-cylindrical block of aluminium (anode), 2-copper wire (cathode), 3-cavity, 4-gas inlet, 5, 6-insulators disks made of Teflon, 7-plasma plume. (Colour only in electronic version)

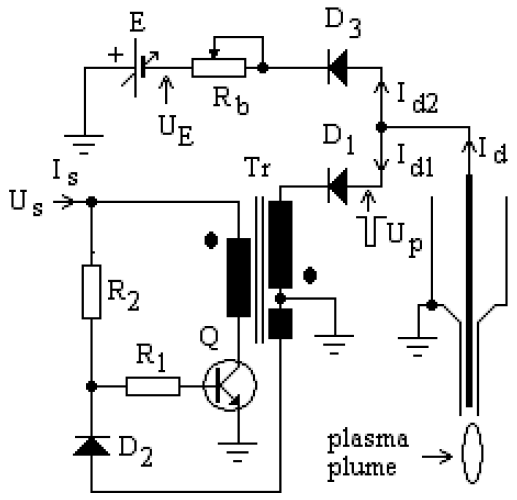

Fig. 2. Electrical circuit of the electrodes

\section{Electrical circuit of the electrodes}

The electrical circuit of the electrodes consists of two voltage sources in parallel connection as shown in Figure 2. One of them is a low power self oscillating FBC able to produce negative high voltage pulses necessary to initiate an electrical discharge between electrodes. The second one (denoted by E in Figure 2) is a conventional dc source which can deliver a few hundred volts at a few hundred milliamps, and is used to sustain the electrical discharge.

The FBC consists of the transformer Tr, bipolar junction transistor Q (BU208), rectifier diode $\mathrm{D}_{1}$ (KYX30), 
blocking diode $\mathrm{D}_{2}$ (BA159) and bias resistors $\mathrm{R}_{1}=180 \Omega$ and $\mathrm{R}_{2}=270 \Omega$, respectively. Accurate descriptions of the FBC can be found in various papers [15-17]. The transistor Q operates as an electronic switch by interrupting periodically the electrical current through the primary winding of the transformer Tr. The energy taken from the dc source is alternately stored as a magnetic field of the transformer core when the switch is on, and, released to the load as a voltage pulse when the switch is off. Generally, amplitude of the output pulses $U_{p}$, oscillating frequency $f$ of the transistor and dc supply current $I_{s}$ depend on the load. Neglecting any losses, the average power $P_{0}$ delivered to the load can be expressed as:

$$
P_{0}=f \Delta W_{p}=\frac{B_{s a t}^{2} S^{2} f}{2 A_{L}}
$$

where $\Delta W_{p}$ is the amount of energy transferred during a single pulse to the load, $B_{\text {sat }}$ is the saturation flux density, while $S$ and $A_{L}$ are, effective cross-sectional area and inductance factor, respectively, of the transformer magnetic core. For a FBC the output pulse length is $t_{p} \approx$ $(1-\delta) / f$ where $\delta$, called duty cycle, represents the proportion of time during which the transistor acts as an on switch. Assuming the output voltage waveform as a series of square pulses of amplitude $U_{p}$ and length $t_{p}$, the peak power $P_{p}$ transferred to the load during a single pulse is $P_{p}=U_{p} I_{p}=f \Delta W_{p} /(1-\delta)$, where $I_{p}$ is the peak current through the load. Consequently, the amplitude of the output pulses is maxim if no load is connected $\left(I_{p}=0\right)$. The leakage currents of the transformer secondary circuit are equivalent to a load permanently connected; therefore, the amplitude of the output voltage pulses is finite. By an appropriate design the open circuit pulses amplitude can achieve several kilovolts, large enough, at atmospheric pressure, to initiate an electrical discharge between the cathode and the aluminium wall of the cavity. For a supply dc voltage $U_{s}=8.5 \mathrm{~V}$ and without load, the FBC presented here operates at $f=5 \mathrm{kHz}$ and $I_{s 0}=0.4 \mathrm{~A}$, yielding negative high voltage pulses with the amplitude $U_{p} \approx 4 \mathrm{kV}$ and length $t_{p} \approx 19 \mu \mathrm{s}$. The electrical power $P_{s 0}=U_{s} I_{s 0}=3.4 \mathrm{~W}$ delivered by dc source is mostly dissipated as heat in FBC electronics components. According to (1), the amount of energy $\Delta W_{p}$ transferred to the load during an output pulse depends only on the dimensions and magnetic properties of the transformer core. The oscillating frequency $f$ is limited by the switching times of the transistor $\mathrm{Q}$ and by the dynamic characteristics of the transformer core, so that, in the case of a practical circuit, there is a maximum average power $P_{0 \max }=f_{\max } \Delta W_{p}$ which could be transferred to the load. Because there is no ballast resistor inserted between the cathode and FBC output, once the electrical discharge has been ignited, electrical parameters of the FBC (supply current, duty cycle and operating frequency) are self-adjusting so that the amplitude of the output pulses $U_{p}$ becomes equal to the discharge voltage $U_{d}$. The duty cycle and oscillating frequency can vary only within a limited range; hence it is not always possible to match its output voltage and available power to the values necessary to sustain the electrical discharge. When matching conditions are not met the electrical discharge is extinguished immediately after it started and the FBC operation becomes unstable. In the case of a given work- 
ing gas, gas pressure and device geometry, the discharge voltage can be assumed to be approximately constant in a wide current range. If only the $\mathrm{FBC}$ is connected to the electrodes $\left(I_{d 2}=0\right)$, the average discharge current $I_{d}=I_{d 1}$ has an upper limit $I_{d \max }=P_{0 \max } / U_{d}$. The FBC output current $I_{d 1}$ cannot be controlled in a simple manner. To overcome these drawbacks, a conventional adjustable output voltage dc source E was made in parallel connection to the electrodes through a variable ballast resistor $\mathrm{R}_{b}=2 \mathrm{k} \Omega$ and a high voltage diode $\mathrm{D}_{3}$ formed by 5 diodes BY2000 in series. The output voltage $U_{E}$ of the dc source $\mathrm{E}$ can be varied in the range $-100 \mathrm{~V}$ to $-500 \mathrm{~V}$. The role of the diode $\mathrm{D}_{3}$ is to separate the dc source E from the FBC. After the electrical arc between electrodes is initiated the discharge current $I_{d}$ is given by the relation:

$$
I_{d}=I_{d 1}+I_{d 2}=I_{d 1}+\left|U_{E}-U_{d}\right| / R_{b}
$$

where $I_{d 1}$ and $I_{d 2}$ represent the discharge current components due to the $\mathrm{FBC}$ and the source E, respectively. As a result, the discharge current can be simply adjusted by varying either the voltage $U_{E}$ or resistance $R_{b}$.

\section{Plasma source operation}

After an electrical discharge is established between the cathode and the aluminium wall of the cavity, it is pushed by the working gas flux through the output hole. As shown in Figure 3, the plasma jet looks similar to an elongated bright plume that can extend about $8 \mathrm{~mm}$ from the output hole to the atmosphere.

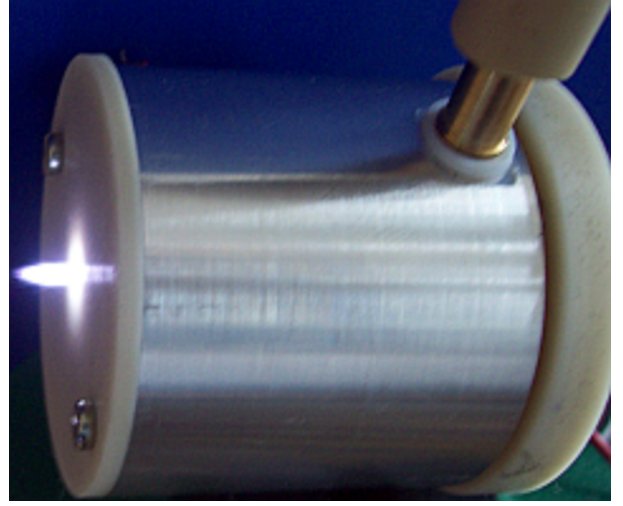

Fig. 3. Photograph of the plasma plume ejecting in the surrounding atmosphere, at an argon flow rate of $5 \mathrm{l} / \mathrm{min}$ and discharge current $I_{d}=100 \mathrm{~mA}$. The plasma source is operated in a non-transferred arc mode. (Colour only in electronic version)

For the discharge current component $I_{d 2}$ varying in the range of $15 \mathrm{~mA}$ to $100 \mathrm{~mA}$ and the argon flow rate between $1.2 \mathrm{l} / \mathrm{min}$ and $10 \mathrm{l} / \mathrm{min}$, the electrical power drawn by the FBC was approximately constant $P_{s}=U_{s} I_{s}=4.59 \mathrm{~W}$. Roughly, the power transferred to the plasma by the FBC can be estimated as $\Delta P \approx P_{s}-P_{s 0}=1.19 \mathrm{~W}$. For comparison, at an argon flow rate of $5 \mathrm{l} / \mathrm{min}$, the power delivered to the plasma by the source E, $P_{d 2}=U_{d} I_{d 2}$ varies in the range from $5 \mathrm{~W}$ to $22.4 \mathrm{~W}$ if $15 \mathrm{~mA}<I_{d 2}<100 \mathrm{~mA}$. The discharge voltage was around $250 \mathrm{~V}$ so that the magnitude of the component $I_{d 1}$ can be estimated as: $I_{d 1} \approx \Delta P / U_{d}$ $=5 \mathrm{~mA}$ and, practically, $I_{d} \approx I_{d 2}$ if $I_{d 2}>50 \mathrm{~mA}$. By neglecting the component $I_{d 1}$, the current-voltage characteristic of the discharge, obtained for an argon flow rate of $5 \mathrm{l} / \mathrm{min}$, is shown in Figure 4. Discharge current component $I_{d 2}$ and voltage $U_{d}$ have been measured directly by using analogue multimetres. As can be seen from Figure 4 , for $I_{d 2}>40 \mathrm{~mA}$, the discharge voltage slightly decreases 


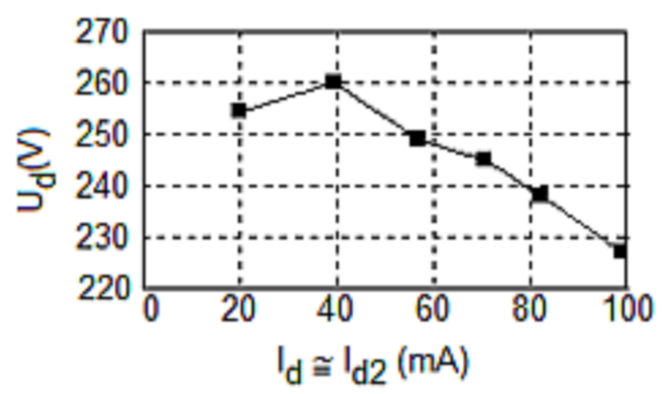

Fig. 4. Current-voltage characteristic of the discharge at an argon flow rate of $5 \mathrm{l} / \mathrm{min}$ and $R_{b}=2 \mathrm{k} \Omega$. The discharge current component $I_{d 1}$ due to the $\mathrm{FBC}$, which is estimated to be around $5 \mathrm{~mA}$, has been neglected.

with the discharge current similarly to a glow discharge $[18,19]$.

After the formation of the plasma plume, under certain operation conditions (discharge current, gas flow and position of the object under plasma treatment), the FBC can be shut down in order to improve global efficiency. However, in this case, plasma plume stability cannot be maintained for more than several seconds after that the electrical discharge between electrodes is interrupted. Usually, to allow a continuous operation, the FBC was permanently connected to the electrodes. To identify the excited species generated by the plasma plume, optical emission spectroscopy has been applied. The emission radiation in the range 300-1000 nm has been collected by an optical fibre by having one end coupled to an OceanOptics HR4000 spectrometer. The other end of the optical fibre was placed near the plasma plume and oriented perpendicular to it. A typical emission spectra in the range $600-1000 \mathrm{~nm}$ is shown in Figure 5. For the presented spectra, the argon

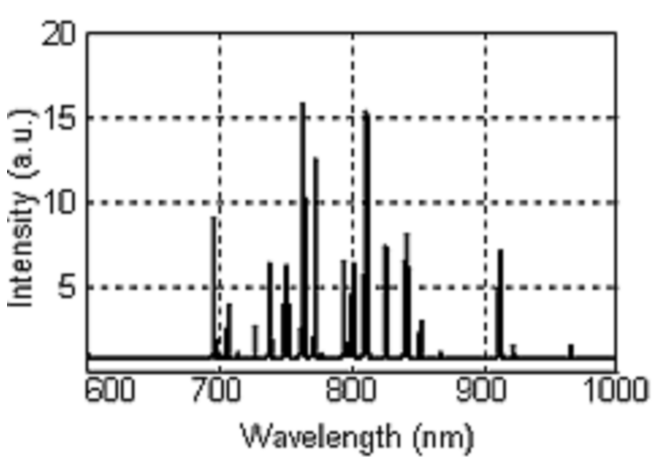

Fig. 5. Emission spectra in the range $600-1000 \mathrm{~nm}$ of the plasma plume, at an argon flow rate of $5 \mathrm{l} / \mathrm{min}$ and discharge current $I_{d}=55 \mathrm{~mA}$.

flow rate and discharge current are $5 \mathrm{l} / \mathrm{min}$ and $55 \mathrm{~mA}$, respectively. The spectra contains, mainly, Ar I lines [20] at 696.5, 706.7, 714.7, 727.3, 738.4, 750.4, 763.5, 772.4, 794.8, 801.5, 811.5, 826.4, 840.8, 842.5, 852.1, 866.8, 912.3, 922.4 and $965.8 \mathrm{~nm}$, with the 763.5 and $811.5 \mathrm{~nm}$ the strongest. In addition an atomic oxygen line at $777.1 \mathrm{~nm}$ was detected due to the opening to the ambient air [21]. The averaged electron density, $N_{e}$, can be estimated from the equation:

$$
N_{e}=\frac{j_{d}}{e \mu_{e} E}=\frac{j_{d}}{e v_{d}}
$$

where $E$ is electric field strength, $j_{d}$ is current density, $\mu_{e}$ is the electron mobility, $v_{d}$ is electron drift velocity and $e=1.602 \times 10^{-19} \mathrm{C}$ is the elementary charge. Electron drift velocity depends on the reduced field $E / p$ and type of the carrier gas. Taking into account the geometry of the electrodes, the electric strength field peak $E_{p}$ can be calculated as:

$$
E_{p}=\frac{U_{p}}{r \ln \left(D_{\min } / d\right)}
$$


At the cathode surface $(r=d / 2), E_{p} \approx 28 \mathrm{kV} / \mathrm{cm}$ while at the anode surface $\left(r=D_{\min } / 2\right), E_{p} \approx 5.4 \mathrm{kV} / \mathrm{cm}$. Considering plasma at atmospheric pressure and the electric field peak calculated at half the distance between the anode and cathode $r_{m}=\left(D_{\min }+d\right) / 4$, it results in $E_{p}=9$ $\mathrm{kV} / \mathrm{cm}$ and the reduced field $E / p=11.8 \mathrm{Vcm}^{-1}$ torr $^{-1}$ which give a value of $v_{d}$ and $\mu_{e}$ for argon as $3 \times 10^{6}$ $\mathrm{cm} / \mathrm{s}$ and $3.3 \times 10^{2} \mathrm{~cm}^{2} V^{-1} \mathrm{~s}^{-1}$, respectively [22]. For the cylindrical surface corresponding to the radius $r_{m}$ current density was estimated as:

$$
j_{d}=\frac{I_{d}}{2 \pi r_{m} L_{0}}
$$

According to (5) current density varies from $0.022 \mathrm{~A} / \mathrm{cm}^{2}$ to $0.044 \mathrm{~A} / \mathrm{cm}^{2}$ for the discharge current $50 \mathrm{~mA}$ to $100 \mathrm{~mA}$ and $L_{0}=13 \mathrm{~mm}$. As a consequence, by using equation (3), electron density was estimated to lie in the interval 4.7 x $10^{10}-9.4 \times 10^{10} \mathrm{~cm}^{-3}$, in the discharge current range 50-100mA. Electron temperature $T_{e}$ can be roughly evaluated by using Einstein's equation, $k T_{e} / e \approx D / \mu_{e}$ where $k=1.38 \times 10^{-23} \mathrm{~J} / \mathrm{K}$ is Boltzmann constant and $D$ is the electron diffusion coefficient. The ratio $D / \mu_{e}$ depends on the reduced field. From [23], in the case of argon, $D / \mu_{e} \approx$ $2 \mathrm{~V}$ hence $T_{e} \approx 2 \mathrm{eV}$. At an argon flow rate of $5 \mathrm{l} / \mathrm{min}$ and discharge current $I_{d 2}=85 \mathrm{~mA}$, the gas temperature measured by means of a thermocouple, at $3 \mathrm{~mm}$ from the output hole of the plasma plume, fluctuates around $130^{\circ} \mathrm{C}$.

\section{Conclusions}

In this paper a plasma source, operating at atmospheric pressure, supplied practically at a relative low dc voltage by means of a simple and inexpensive electrical circuit, is presented. Circuit topology enables an easy control of the discharge current and a high efficiency of the electrical energy to plasma energy conversion. The described plasma source is mainly intended for the surface plasma treatment of various materials, being able to operate both in a transferred and non-transferred arc mode, without any modification of the set-up. Thus, both conductive and nonconductive substrates can be exposed to the action of the plasma. Its characteristics (electron density, electron temperature and gas temperature) are similar to those of the atmospheric pressure plasma jet [18]. This work was supported by National Authority for Scientific Research from Romania, under contract PN 09.39.03.01/2009-2011.

\section{References}

1. G. S. Selwyn, H. W. Herrmann, J. Park and I. Henins, Contrib. Plasma Phys. 41, 610 (2001)

2. M. Laroussi, D. A. Mendis and M. Rosenberg, New Journal of Physics 5, 41.1 (2003)

3. K. H. Becker, K. H. Schoenbach and J. G. Eden, J. Phys. D: Appl. Phys. 39, R55 (2006)

4. K. Ostrikov and A. B. Murphy, J. Phys. D: Appl. Phys. 40, $2223(2007)$

5. T. Nozaki and K. Okazaki, Plasma Process. Polym. 5, 301 (2008) 
6. M. Saiepour and J. E. Harry, J. Phys. D: Appl. Phys. 23, 1129 (1990)

7. G. Penghui, N. Hayashi, S. Ihara, S. Satoh and C. Yamabe in Proc. of Hakone 8, Pühajärve, Estonia, 2002, p.347

8. C. Louste, G. Artana, E. Moreau and G. Touchard, Journal of Electrostatics 63, 615 (2005)

9. K. Hensel, S. Sato and A. Mizuno, Chemické Listy 102, s1318 (2008)

10. C. H. Kruger, C. O. Laux, L. Yu, D. M. Packan, L. Pierrot, Pure Appl. Chem. 74, 337 (2002)

11. S. Ben-Yaakov, M. Gulko and A. Giter in Proc. of APEC1996, San Jose, CA, 1996, Vol. 2, p.634

12. G. G. Lister, J. E. Lawler, W. P. Lapatovich and V. A. Godyak, Rev. Mod. Phys. 76, 541 (2004)

13. W. S. Kim, B. H. Cho and K. C. Lee in Proc. of APEC2005, Austin, TX, 2005, Vol. 2, p.1043

14. Y. Hu and M. M. Jovanović, in Proc. of APEC-200\%, Anaheim, CA, 2007, p. 268

15. J.-B. Lio, M.-S. Lin, D.Y. Chen and W.-S. Feng, Electronics Letters, 32, 1429 (1996)

16. B. T. Irving and M. M. Jovanović in Proc. of APEC-2002, Dallas, TX, 2002, Vol.2, p. 897

17. M. Ferdowsi, A. Emadi, M. Telefus and C. Davis, IEEE Transactions on Power Electronics 20, 798 (2005)

18. A. Schütze, J.Y. Jeong, S. E. Babayan, J. Park, G. S. Selwyn and R. F. Hicks, IEEE Transactions on Plasma Science 26, 1685 (1998)

19. Z. Machala, E. Marode, C. O. Laux and C. H. Kruger, J. Adv. Oxid. Technol. 7, 133 (2004)

20. W. Whaling, W. H. C. Anderson, M. T. Carle, J. W. Brault and H. A. Zarem, J. Res. Natl. Inst. Stand. Technol. 107, 149
21. J. E. Sansonetti and W. C. Martin, NIST Handbook of Basic Atomic Spectroscopic Data, [Online]. Available: http://www.nist.gov/pml/data/handbook/index.cfm 22. V. Lisovskiy, J-P. Booth, K. Landry, D. Douai, V. Cassagne and V. Yegorenkov, J. Phys. D: Appl. Phys. 39, 660 (2006)

23. V. A. Lisovskiı̌, Tech. Phys. Lett. 24, 308 (1998) 